\title{
tratamientos térmicos del hormigón
}

\author{
J. CalleJa, Dr, en Ciencias Químicas
}

\section{INTRODUCCION}

En la industria de la construcción y en la de la prefabricación de elementos constructivos a base de hormigones y morteros, interesa por múltiples razones acelerar y acortar los procesos de fraguado y de endurecimiento.

Según las circunstancias, esto puede conseguirse de muy diversas formas: a) por empleo de conglomerantes especiales: cementos de altas resistencias iniciales o de endurecimiento rápido, cemento aluminoso, etc.; b) por empleo de aceleradores de fraguado $y$ de endurecimiento a todas las edades: tipo cloruro cálcico, por ejemplo; c) por curado o tratamiento térmico del conglomerado. Los dos primeros procedimientos pueden calificarse de químicos, mientras que el tercero entra en la categoría de los físicos. La realidad es que unos y otros tienen una base fisicoquímica.

Estos métodos distintos, en algunos casos no se excluyen mutuamente, sino que se complementan. Así, es compatible el empleo de un acelerador con un cemento portland de endurecimiento rápido o con un curado térmico. En otros casos, en cambio, no es aconsejable simultanear dichos métodos; tal sucede con el empleo de los cementos de altas resistencias y los tratamientos térmicos. Casos hay también en que una simultaneidad es totalmente improcedente, como ocurre con el empleo de cloruro cálcico con cemento aluminoso, o de éste en un curado por calor.

Es en la prefabricación de piezas de hormigón donde los tratamientos térmicos han alcanzado mayor desarrollo, combinados o no con el empleo de aceleradores. Las ventajas técnicas y económicas que estos tratamientos aportan son: aumento de la producción; ahorro de moldes y mayor rendimiento de éstos al poder desenmoldar en menor tiempo; ahorro de espacio de curado y almacenamiento; posibilidad de una más inmediata puesta en servicio de las piezas, etc., sin contar con el ahorro en concepto de mano de obra, todo lo cual implica una considerable mejora de la productividad.

Los tratamientos térmicos requieren una estrecha vigilancia, ya que no basta conseguir con ellos unas buenas resistencias mecánicas a corto plazo, si no se evita al máximo la caída de las mismas a plazos normales y largos, cosa que en cierta medida suele suceder con frecuencia. En general, las resistencias a la flexión permiten juzgar mejor que las de compresión acerca de los efectos de un tratamiento térmico. 
En el Instituto "Eduardo Torroja" de la Construcción y del Cemento (I. E. T. c. c.) se han llevado a cabo estudios experimentales acerca del empleo de aceleradores del fraguado y del endurecimiento de los conglomerantes*, así como sobre la influencia de la temperatura en el fraguado y sobre la aceleración de éste por calefacción eléctrica**. Igualmente se han verificado ensayos sobre productos de adición y sobre tratamientos térmicos, los cuales no han sido objeto de publicación, pero han permitido fijar condiciones óptimas de empleo o de aplicación, confirmar o desechar hipótesis y, en definitiva, adquirir experiencia.

Estos ensayos, así como las consultas formuladas al I. E. T. c. c., en una determinada época, aconsejaron la publicación en su momento de una nota *** con lo más destacado acerca de los tratamientos térmicos del hormigón mediante calefacción con vapor libre.

Con posterioridad ha habido ocasión de corroborar de manera experimental y directa las conclusiones que destacaban en aquella nota.

Todo ello ha culminado más recientemente en la presente publicación sobre curado y tratamientos térmicos, cumpliendo así con lo anunciado y prometido en ocasiones anteriores.

\section{GENERALIDADES}

\subsection{Termoquímica de la hidratación y de los procesos de curado térmico del cemento.}

La hidratación (fraguado y endurecimiento) de los conglomerantes hidráulicos, es un conjunto de procesos o reacciones químicas.

En la cinética de los procesos químicos intervienen como variables la presión, la temperatura, la concentración y la acción de catalizadores eventuales.

La hidratación de los conglomerantes transcurre prácticamente siempre a la presión atmosférica ordinaria, en general, sin participación de una fase gaseosa activa, por lo cual la presión no influye en el desarrollo de las correspondientes reacciones.

El efecto combinado de la presión y de la temperatura en los tratamientos con vapor en autoclave merece una mención especial.

La influencia de la concentración y de los catalizadores (aceleradores o retardadores) es la previsible y requiere también un estudio aparte ****.

Todo proceso químico se ve acelerado por la elevación de la temperatura, hasta tal punto que cada aumento de ésta en $10^{\circ} \mathrm{C}$, aproximadamente duplica la velocidad de reacción.

* J. Calleja: "El Cloruro Cálcico en la Construcción". Manuales y Normas del I. E, T. c. c. Madrid, 1957.

J. CALleja: "El Cloruro Cálcico como Acelerador en la Prefabricación del Hormigón". Monografía número 185 del I. E. T, c. c. Madrid, 1958.

* J. Caldeja: "Nuevas Técnicas para el estudio del Fraguado y Endurecimiento de los Aglomerantes Hidráulicos. Influencia de la Temperatura en el Fraguado". Revista de Ciencia Apticada VI (29/6), 506-516 (1952).

J. CALLEJa: "Nuevas Técnicas para el Estudio del Fraguado y Endurecimiento de los Agiomerantes Hidráulicos. Aceleración del Fraguado mediante Calefacción por Efecto Joule". Revista de Ciencia Aplicada VII (35/6), 494-505 (1953).

*** J. Calleja: "Tratamientos Térmicos del Hormigón". Materiates de Construcción. Ultimos Avances (I. E. T. c. c.) núm. 85 , págs. 3-6, enero-febrero 1958.

***** J. Calleja y B. Bacle: "Aditivos para el Hormigón". Manuales y Normas del I. E. T. c. c. Madrid (en prensa). 
En el caso del cemento portland y de los conglomerantes a base del mismo, la explicación, fundada en la constitución química de dichos conglomerantes, es fácil por vía teórica. $\mathrm{El}$ cemento portland está constituido por dos silicatos cálcicos (el tricálcico: $\mathrm{SC}_{3}=$ $=\mathrm{SiO}_{2} .3 \mathrm{CaO}$ y el bicálcico: $\mathrm{SC}_{2}=\mathrm{SiO}_{2} \cdot 2 \mathrm{CaO}$ ), un aluminato (el tricálcico: $\mathrm{AC}_{3}=\mathrm{Al}_{2} \mathrm{O}_{3}$. . $3 \mathrm{CaO}$ ) y un ferrito-aluminato (el tetracálcico: $\mathrm{FAC}_{4}=\mathrm{Fe}_{2} \mathrm{O}_{3} . \mathrm{Al}_{2} \mathrm{O}_{3}, 4 \mathrm{CaO}$ ).

La velocidad de disolución y de reacción de los dos silicatos y del aluminato con el agua aumenta con la temperatura; la del ferrito-aluminato disminuye. En conjunto y en general, dado el escaso contenido de $\mathrm{FAC}_{4}$ de los cementos, en comparación con los contenidos de los otros constituyentes, el aumento de temperatura ejerce una acción aceleradora de la hidratación del cemento portland.

En el caso de los cementos siderúrgicos y puzolánicos (a base de portland) la actividad de la escoria o de la puzolana depende de la alcalinidad del medio, la cual es proporcionada por la cal de hidrólisis de los silicatos, y ésta, como queda expuesto, se forma más rápidamente cuanto mayor es la temperatura.

En el caso de los cementos no portland (aluminosos o sobresulfatados) ocurren fenómenos especiales que les hacen no aptos para los tratamientos térmicos.

Los procesos de hidratación transcurren más rápidamente, por lo tanto, si se aporta calor al sistema reaccionante, ya que la precipitación de hidratos formados por geles microcristalinos constitutivos de la pasta hidratada (a causa del fraguado y del endurecimiento), resulta asimismo acelerada. La aportación del calor puede efectuarse de muy diversas formas.

En primer lugar, hay que tener en cuenta que el fenómeno de la hidratación es exotérmico, esto es, transcurre con desprendimiento del calor (calor de hidratación). Este calor puede disiparse en el ambiente o acumularse en la masa que forma el sistema reaccionante; ambas cosas pueden suceder en muy variada medida, y dar lugar, en circunstancias ideales, a dos situaciones extremas.

La primera corresponde al caso en que el calor de hidratación se disipe con la misma velocidad con que se desprende en el proceso. En este caso no hay elevación de la temperatura en el sistema y la hidratación se verifica prácticamente en condiciones isotérmicas. No hay, pues, aceleración por efecto térmico.

La segunda corresponde al caso contrario en que el calor no se disipe en absoluto, acumulándose totalmente en la masa reaccionante y provocando una elevación de temperatura en el sistema. Entonces la hidratación transcurre prácticamente en condiciones adiabáticas y el proceso se autoacelera por efecto térmico.

En la realidad no se da ninguna de estas dos situaciones extremas, sino otras intermedias más o menos próximas a una cualquiera de ellas, por lo cual, según los casos, habrá que contar también, más o menos, con una cierta acción térmica. Esta es más notoria en el caso de la hidratación del cemento en grandes masas de hormigón con una baja relación de superficie a volumen, tal como sucede en las grandes presas.

En circunstancias normales y para unas condiciones fijadas, la curva de desprendimiento del calor con el tiempo (calor de hidratación-tiempo) en una masa de cemento, mortero u hormigón que se hidrata tiene una forma característica (figuras 1, $a$-I y $a$-II) *. A ella corresponde en las mismas condiciones una curva temperatura-tiempo también ca-

"Los gráficos de las figuras expuestas son meramente esquemáticos. 
racterística (figuras 2, $a$-I y $a$-II). Las curvas representadas son algo distintas en uno y otro caso, dependiendo de la naturaleza (tipo, clase y calidad) de los conglomerantes. Así, para los cementos fríos (de moderado o bajo calor de hidratación), las curvas son más ten-

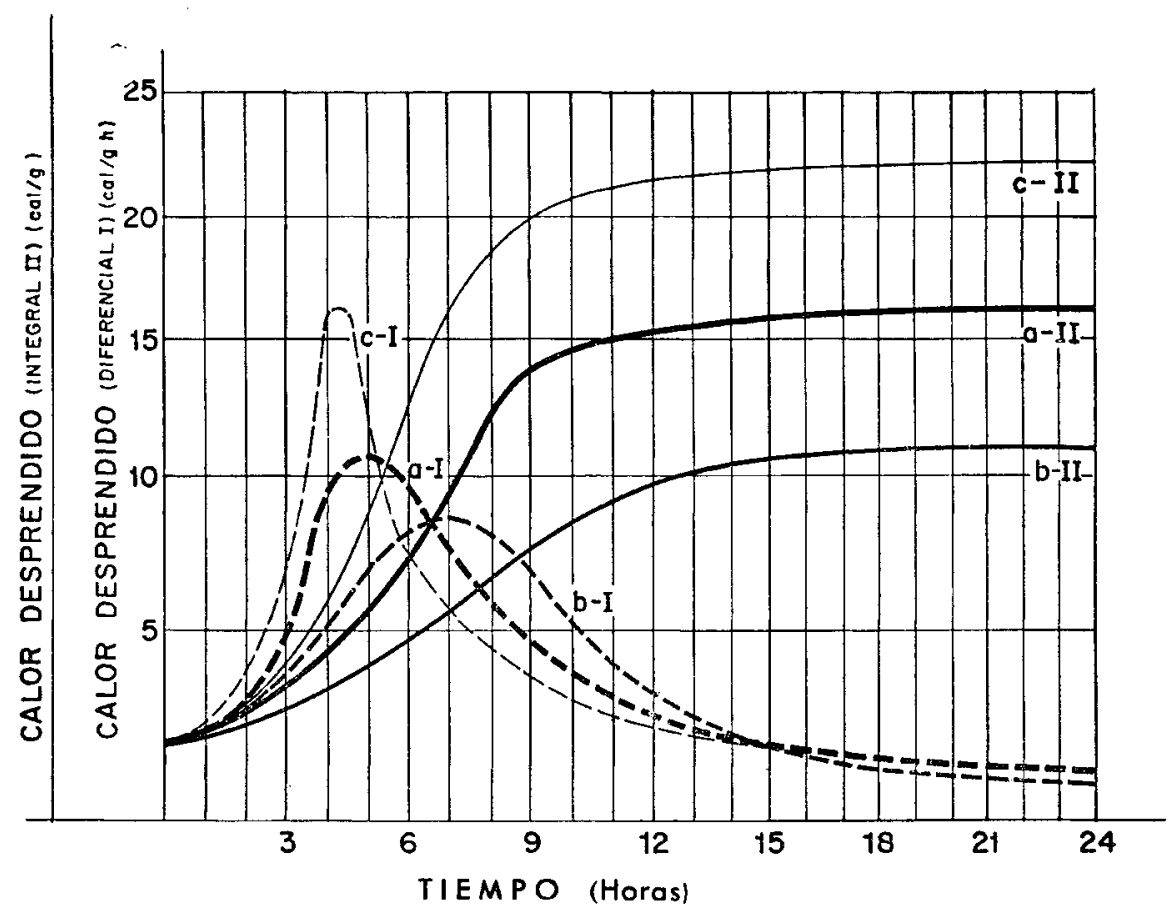

Fig. 1

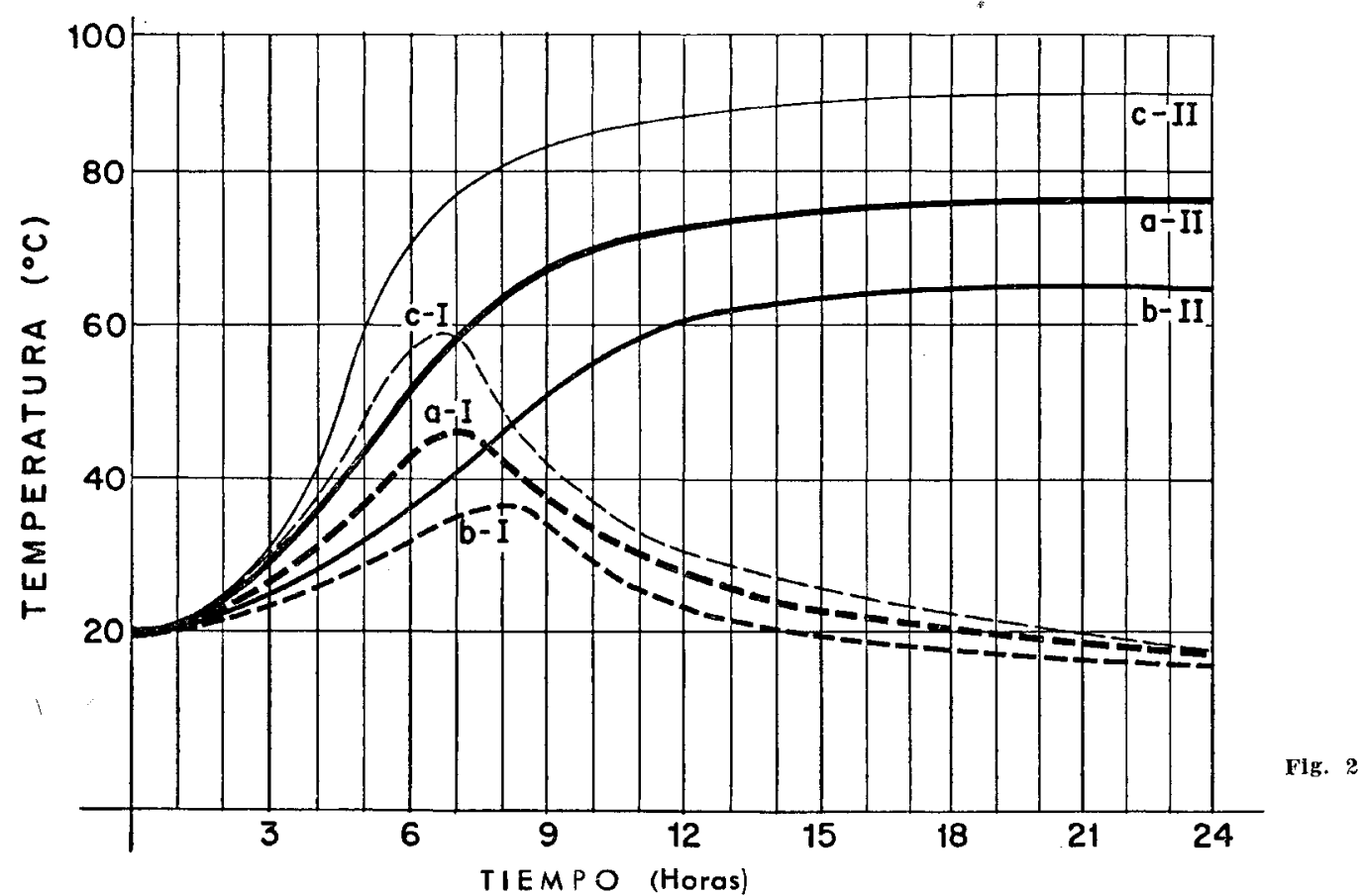

didas (figuras 1, b-I y b-II, y 2, b-I y b-II), mientras que para cementos calientes (de elevado calor de hidratación, ricos en silicato tricálcico y en aluminato tricálcico) las curvas son más abruptas (figuras 1, c-I y c-II, y 2, c-I y c-II). En la figura 1, las curvas II son in- 
tegrales (calor total desprendido) y las I diferenciales (velocidad de desprendimiento de calor). En la figura 2 las curvas II corresponden a condiciones adiabáticas y las I a condiciones ordinarias, no adiabáticas.

Los cementos calientes tienen, por tanto, un fraguado y un endurecimiento más acelerado en igualdad de condiciones, por lo que constituyen los conglomerantes llamados de endurecimiento rápido, de altas resistencias iniciales o a corto plazo, etc. Con ellos a veces no es precisa, ni siquiera conveniente, la aplicación de tratamientos térmicos aceleradores.

El calor de hidratación, más o menos acumulado, es el que en los tratamientos térmicos hace que la temperatura en la masa del hormigón llegue a ser superior a la del recinto en el que se efectúa el tratamiento, pese a que en el comienzo, y durante una buena parte del mismo, suceda a la inversa.

\subsection{El factor humedad en los tratamientos térmicos.}

Para la hidratación es preciso el mantenimiento de un contenido de agua en la masa de cemento que fragua, y de un estado higrométrico adecuado en el ambiente, a fin de evitar pérdidas de agua por evaporación y desecaciones, por lo que se precisa una atmósfera saturada de humedad.

Se suele hablar de secado de hormigón como de algo conveniente para las resistencias de las piezas prefabricadas, cuando sucede justamente lo contrario, al menos por lo que respecta a las resistencias iniciales. El secado conviene cuando el hormigón tiene ya una cierta edad o una cierta resistencia adquirida por un curado en el que la humedad ha sido suficiente.

La falta de humedad hace que la hidratación transcurra anormalmente, to cual sucede además de forma imperceptible, pues con resistencias a la compresión aceptables, las resistencias a la tracción, que son las más afectadas por una humedad insuficiente durante el curado, pueden ser escasas y dar lugar a piezas frágiles.

Dada la realidad termodinámica de que en el aire saturado de humedad la presión del vapor saturante crece muy rápidamente con la temperatura, es comprensible la dificultad de mantener una humedad suficiente en contacto con la superficie de las piezas. Las caras libres de éstas alcanzan antes una temperatura más elevada, puesto que la calefacción se efectúa de fuera hacia adentro. Por ello la tensión de vapor es mayor en dichas caras exteriores, y si el ambiente exterior no alcanza el $100 \%$ de humedad relativa a la temperatura en cuestión, hay desequilibrio y evaporación con pérdida superficial de agua, que no se compensa inmediatamente con agua del interior de la pieza, pues el proceso de difusión del agua desde el interior de la masa del hormigón hacia la superficie es lento. Así, pues, se produce una desigual distribución del agua en el material. Por otra parte, el hecho de registrar una humedad relativa a saturación no quiere decir que no se haya producido desecación, porque parte de esa humedad puede haber provenido del propio hormigón, en virtud del mecanismo de difusión citado.

Debe tenerse en cuenta esto en todo tratamiento térmico, que más bien puede y debe calificarse por ello de higrotérmico. 


\section{ACELERACION TERMICA DEL FRAGUAdo}

El tiempo de fraguado se acorta en general al calentar y elevar la temperatura del conglomerante que fragua. Se exceptúan de este comportamiento algunos cementos especiales, entre los cuales se encuentran los aluminosos y los sobresulfatados.

Los resultados expuestos en lo que sigue, se refieren a cementos portland y, a lo sumo, a los constituidos a base de clínker portland (siderúrgicos y puzolánicos).

La acción de la temperatura en el fraguado presenta dos aspectos diferentes: uno, el de la influencia de pequeños cambios espontáneos de la temperatura ambiente, y otro, el del efecto de las temperaturas altas, provocadas ex profeso.

\subsection{Influencia de los cambios de la temperatura ambiente.}

Cuando la temperatura ambiente crece, se elevan no sólo los valores iniciales, sino también los finales, e incluso los máximos alcanzados por la temperatura del mortero u hormigón a lo largo del proceso de fraguado, con lo cual éste se adelanta, sobre todo por lo que respecta a su final.

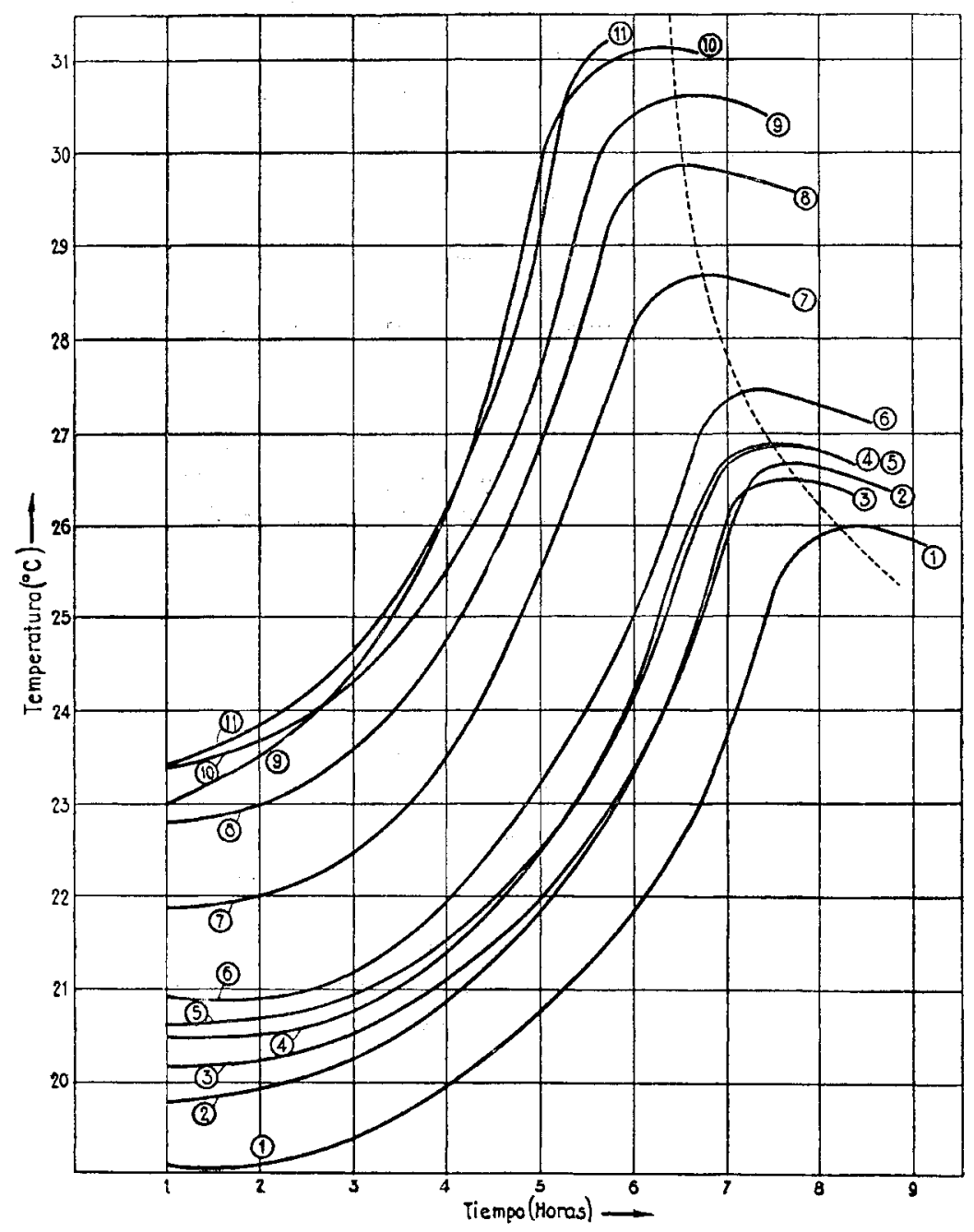


Así lo ponen de manifiesto los datos del cuadro 1 y las curvas temperatura-tiempo del gráfico de la figura 3 (obtenidas en condiciones próximas a las adiabáticas), cuyos máximos, que representan los finales de fraguado, se desplazan hacia la izquierda a medida que aumenta la temperatura inicial.

Un ensayo de fraguado, basado en la observación de las características mecánicas del conglomerado, no permite apreciar, por lo menos fácil y cómodamente, estos hechos. Pero con la consideración de variables de naturaleza eléctrica es posible conseguirlo, y así lo demuestran las curvas resistencia eléctrica-tiempo en el gráfico de la figura 4, correspondiente a las curvas de la figura 3 y a los datos del cuadro 1: los mínimos de dichas curvas representan los finales de fraguado*. Puede apreciarse que, en este caso, un aumento de $5^{\circ} \mathrm{C}$ en las temperaturas, tanto del ambiente como de las probetas, supone un adelanto de unas dos horas en el final del fraguado.

Según esto, considerar que un cemento dado tiene el final de fraguado al cabo de tal o cual tiempo en las "condiciones normales" en que ordinariamente se utiliza, tiene menos valor, mientras no se especifique en qué condiciones precisas de temperatura se lleva a cabo la prueba y, a ser posible, de qué magnitud es la acción aceleradora de la temperatura en el fraguado del cemento en cuestión, para intervalos de la misma correspondientes a las condiciones reales más probables de su empleo. Porque, según el clima de la localidad, la época del año, etc., no es difícil encontrarse con variaciones de temperatura

Fig. 4

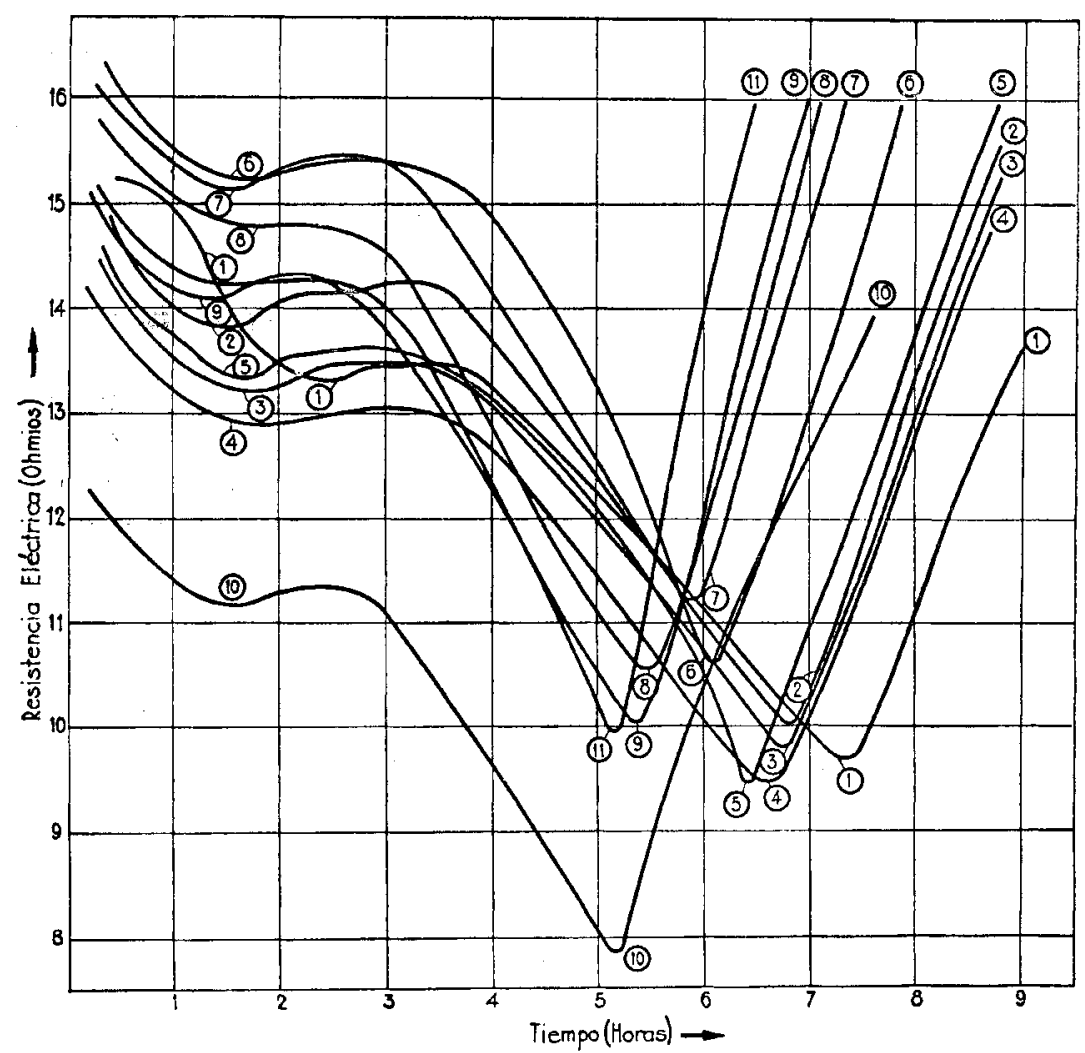

* J. Calteja: "Nuevas Técnicas para el Estudio del Fraguado y Endurecimiento de los Aglomerantes Hidráulicos". Monografías núms. 109 (1950) y 134 (1953) del I. E. T. c. c. Anales Real Soc. Esp. Fis. Quím., 48 (9-10) 705-712 (1952)._Revista de Ciencia Aplicada, VI (29/6), 506-516 (1952); VII (35/6), 4.94-505 (1952). 
en el ambiente y en el agua de amasado superiores a $5^{\circ} \mathrm{C}$, las cuales, según lo expuesto, pueden dar lugar a un adelanto o retardo de dos horas y a veces más en el final del fraguado.

Esto interesa en prefabricación (extracción de piezas de los moldes), en inyecciones de pastas y morteros, en casos de retraso en la puesta en obra de hormigones, etc.

\section{CUADRO 1}

\begin{tabular}{|c|c|c|c|c|c|c|c|c|c|c|}
\hline \multirow{3}{*}{ 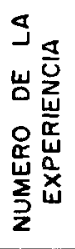 } & \multicolumn{6}{|c|}{ TEMPERATURA $\left({ }^{\circ} \mathrm{C}\right)$} & \multicolumn{4}{|c|}{ FRAGUADO } \\
\hline & \multicolumn{3}{|c|}{ DEL AMBIENTE } & \multicolumn{3}{|c|}{ DE LA PROBETA } & \multicolumn{2}{|c|}{ CURVAS $T-t$} & \multicolumn{2}{|c|}{ CURVAS R-t } \\
\hline & INICIAL & $\begin{array}{l}\text { MA- } \\
\text { XIMA }\end{array}$ & FINAL & INICIAL & $\begin{array}{l}\text { MA- } \\
\text { XIMA }\end{array}$ & FINAL & $\begin{array}{l}\text { PRIN- } \\
\text { CIPIO }\end{array}$ & FIN & $\begin{array}{l}\text { PRIN- } \\
\text { CIPIO }\end{array}$ & FIN \\
\hline 1 & 19,2 & 19,5 & 18,9 & 19,0 & 26,1 & 25,9 & 2,00 & 8,15 & 2,00 & 7,20 \\
\hline 2 & 19,3 & 20,0 & 19,2 & 19,2 & 26,8 & 26,5 & 1,45 & 7,35 & 1,45 & 6,55 \\
\hline 3 & 19,3 & 19,3 & 19,2 & 19,7 & 26,6 & 26,4 & 1,45 & 7,00 & 1,45 & 6,40 \\
\hline 4 & 19,2 & 20,0 & 19,6 & 20,1 & 26,9 & 26,7 & 2,00 & 7,22 & 1,45 & 6,30 \\
\hline 5 & 19,4 & 20,0 & 19,6 & 20,7 & 26,9 & 26,7 & 2,00 & 7,22 & 1,45 & 6,25 \\
\hline 6 & 27,3 & 20,9 & 20,5 & 20,8 & 27,6 & 27,3 & 1,40 & 7,00 & 1,30 & 6,30 \\
\hline 7 & 21,0 & 22,2 & 21,3 & 21,4 & 28,7 & 28,4 & 1,30 & 6,42 & 1,30 & 5,50 \\
\hline 8 & 23,5 & 23,5 & 22,6 & 22,2 & 29,9 & 29,6 & 1,45 & 6,30 & 1,30 & 5,25 \\
\hline 9 & 24,2 & 24,2 & 23,0 & 22,9 & 30,6 & 30,4 & 1,15 & 6,30 & 1,20 & 5,25 \\
\hline 10 & 22,7 & 24,6 & 24,0 & 22,0 & 31,2 & 31,0 & 1,15 & 6,22 & 1,30 & 5,10 \\
\hline 11 & 23,3 & 25,2 & 24,3 & 22,5 & 31,8 & 31,1 & - & 6,20 & 1,30 & 5,10 \\
\hline
\end{tabular}

\subsection{Influencia de la elevación de temperaturas por encima de los valores normales.}

El trazado de las curvas resistencia eléctrica-tiempo, permite destacar el efecto acelerador de los aumentos notables de temperatura (figuras 5 a 12), tanto en el principio $p$ como sobre todo en el final $f$ y en el intervalo de fraguado $i$ (figura 13). En algunas de las gráficas (figuras 5 a 9) se incluyen las curvas de fraguado correspondientes a una temperatura ambiente de $23^{\circ}$ a $25^{\circ} \mathrm{C}$.

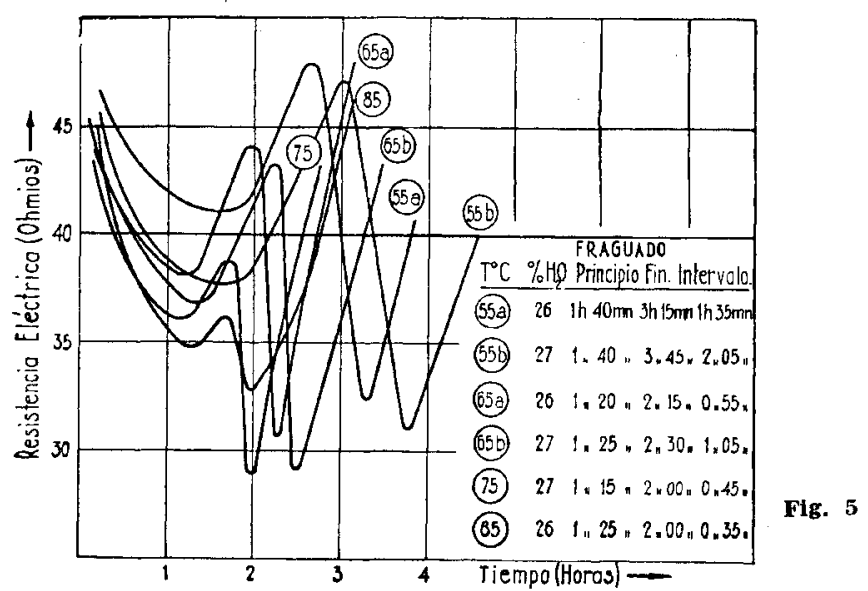




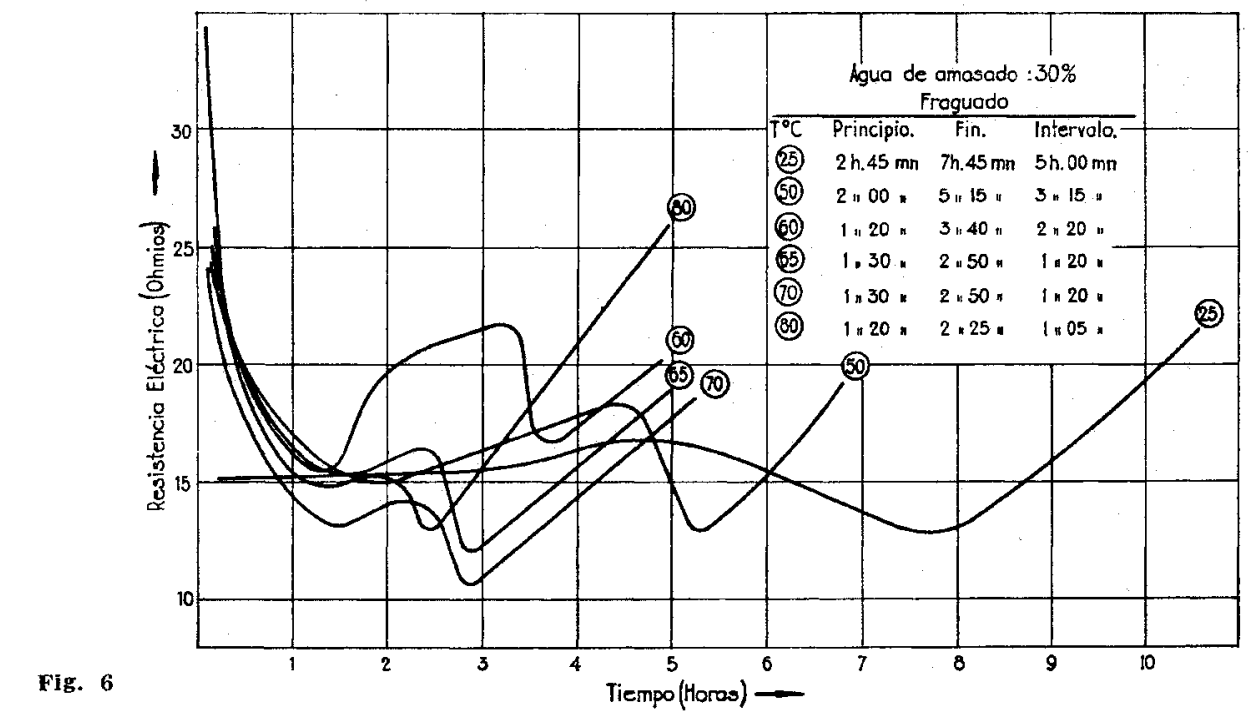

Fig. 7
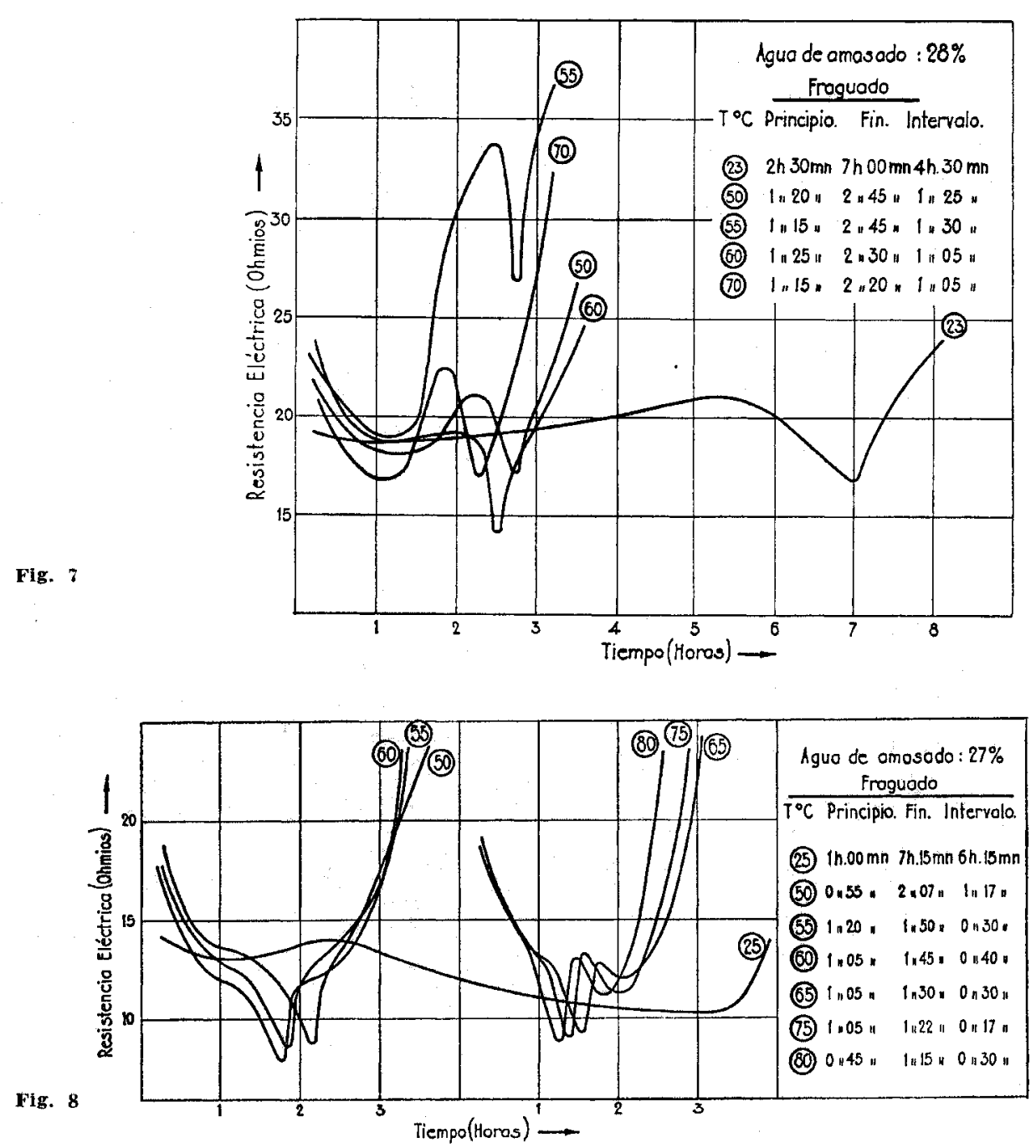

65 


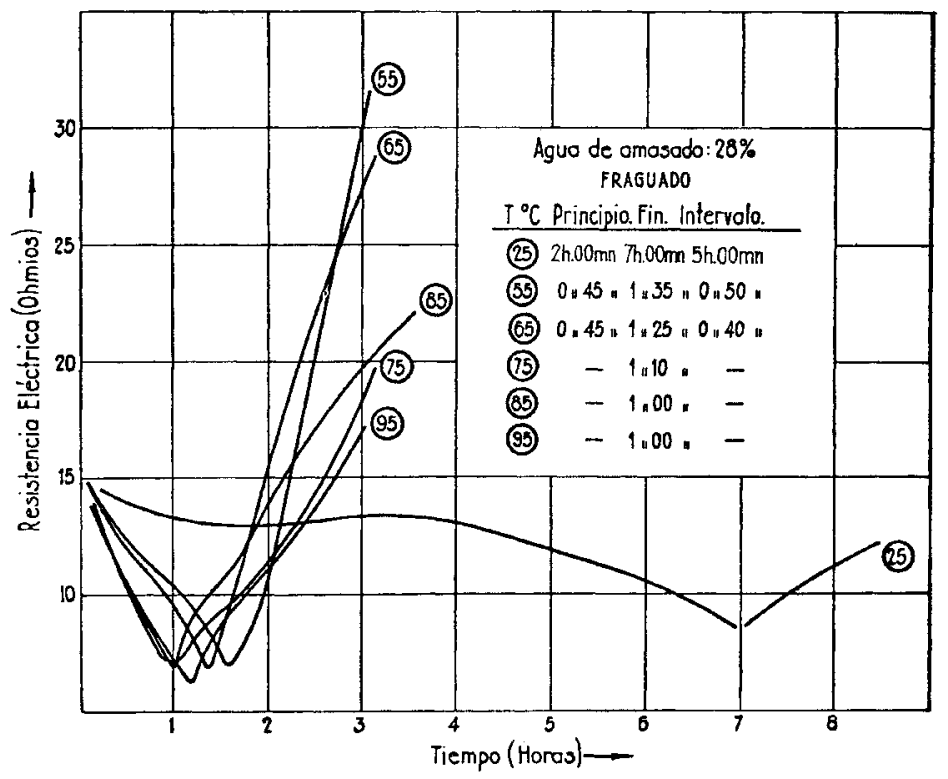

Fig. 9

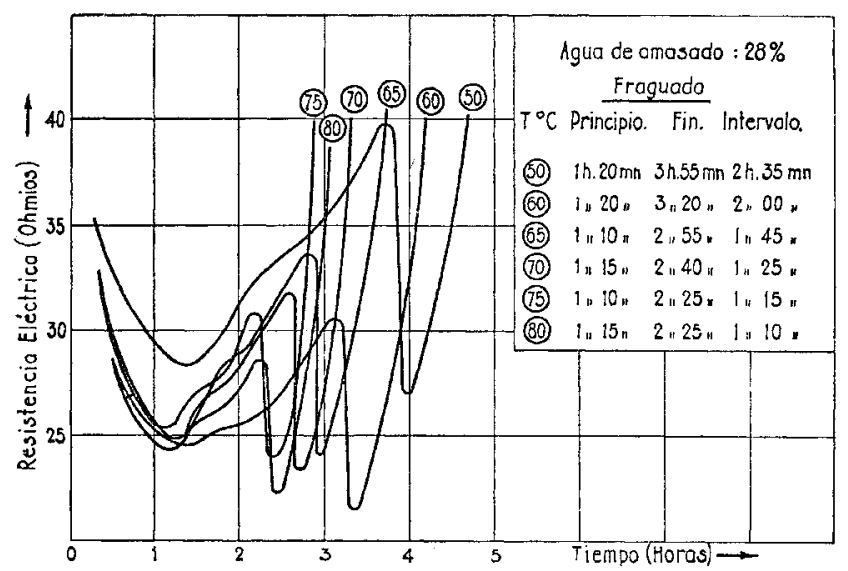

His. 10

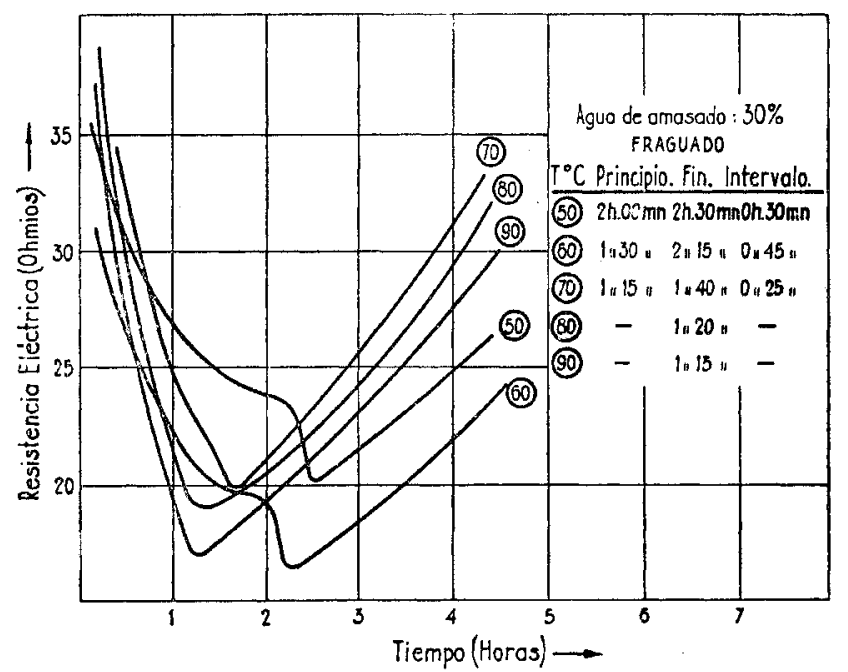

Fig. 11 


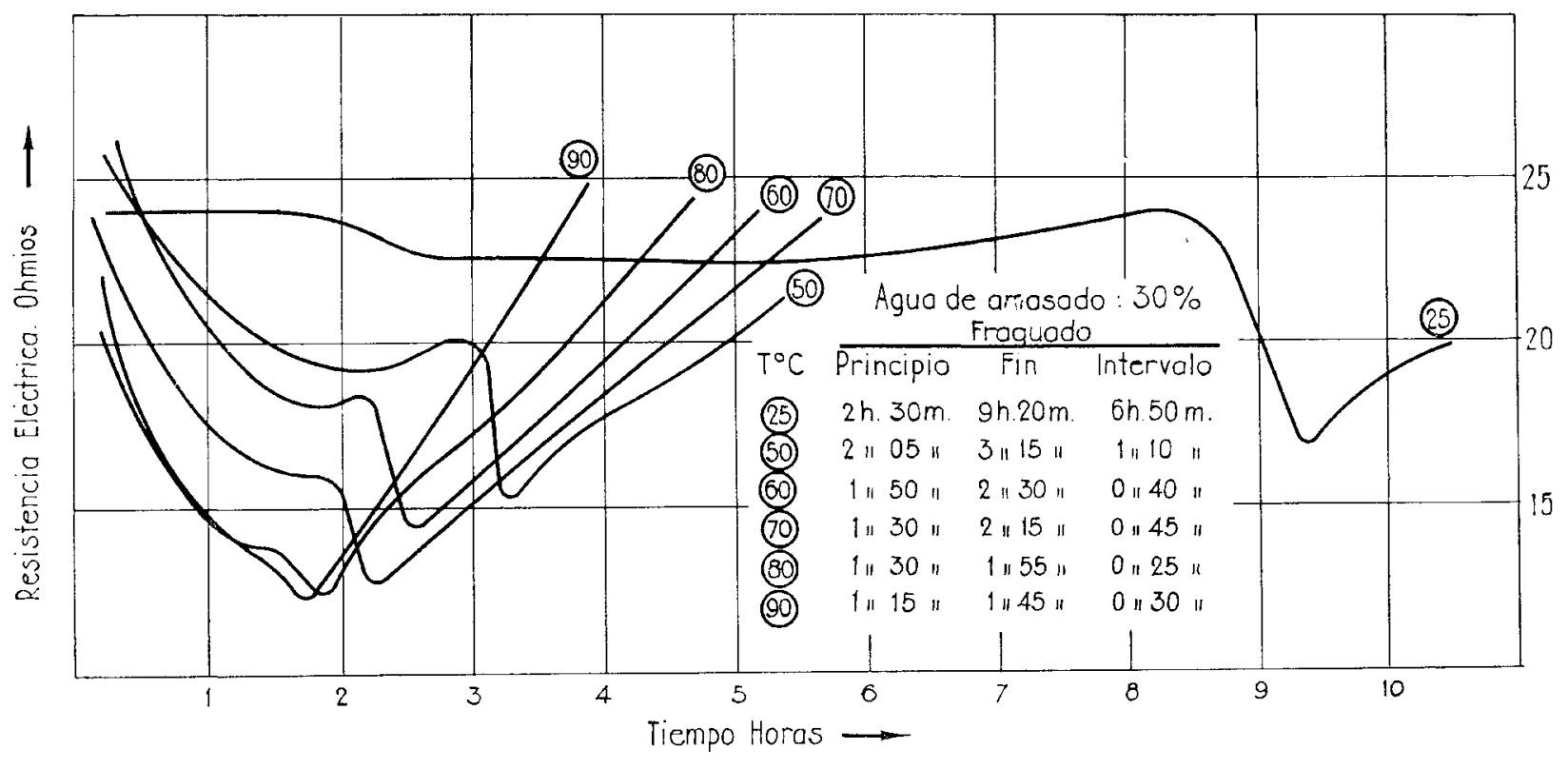

F1E. 12

El efecto acelerador depende de la naturaleza y composición química del cemento, y también de su finura y de la cantidad de agua en la pasta o mortero, pudiéndose establecer con carácter muy amplio y general el hecho de que, para pastas puras de cemento portland con una consistencia normal, la elevación de la temperatura al doble de su valor inicial (de $25^{\circ}$ a $50^{\circ} \mathrm{C}$ ) supone por término medio un adelanto del final del fraguado de la mitad del tiempo necesario para éste (de ocho a cuatro horas), es decir, reduce el tiempo de fraguado a la mitad. De otro modo, para una temperatura ambiente superior a $50^{\circ} \mathrm{C}$, puede conseguirse la totalidad del fraguado en un período de tiempo no superior a cinco horas, en la generalidad de los casos.

La influencia de la cantidad de agua puede apreciarse en las figuras 5, 14, 15, 16, 17 y 18.

La influencia del aumento de la temperatura en el comienzo del fraguado es menos notoria y, en cuanto al final, los efectos son más destacados en el intervalo de temperaturas comprendido entre $45^{\circ}$ y $65^{\circ} \mathrm{C}$.

El cuadro general de la acción de la temperatura en el principio y en el final del fraguado puede verse en el gráfico esquemático de la figura 19.

El estudio del fraguado a temperaturas superiores a las normales tiene interés en el caso de los tratamientos térmicos en autoclaves, cámaras o balsas de curado. Si bien los métodos mecánicos clásicos, generalmente empleados para detectar el final del fraguado, no pueden ser aplicados para obtener un conocimiento del mismo en tales condiciones, las técnicas de naturaleza eléctrica (curvas resistencia eléctrica-tiempo), se prestan bien, como queda demostrado, para dicho fin. 


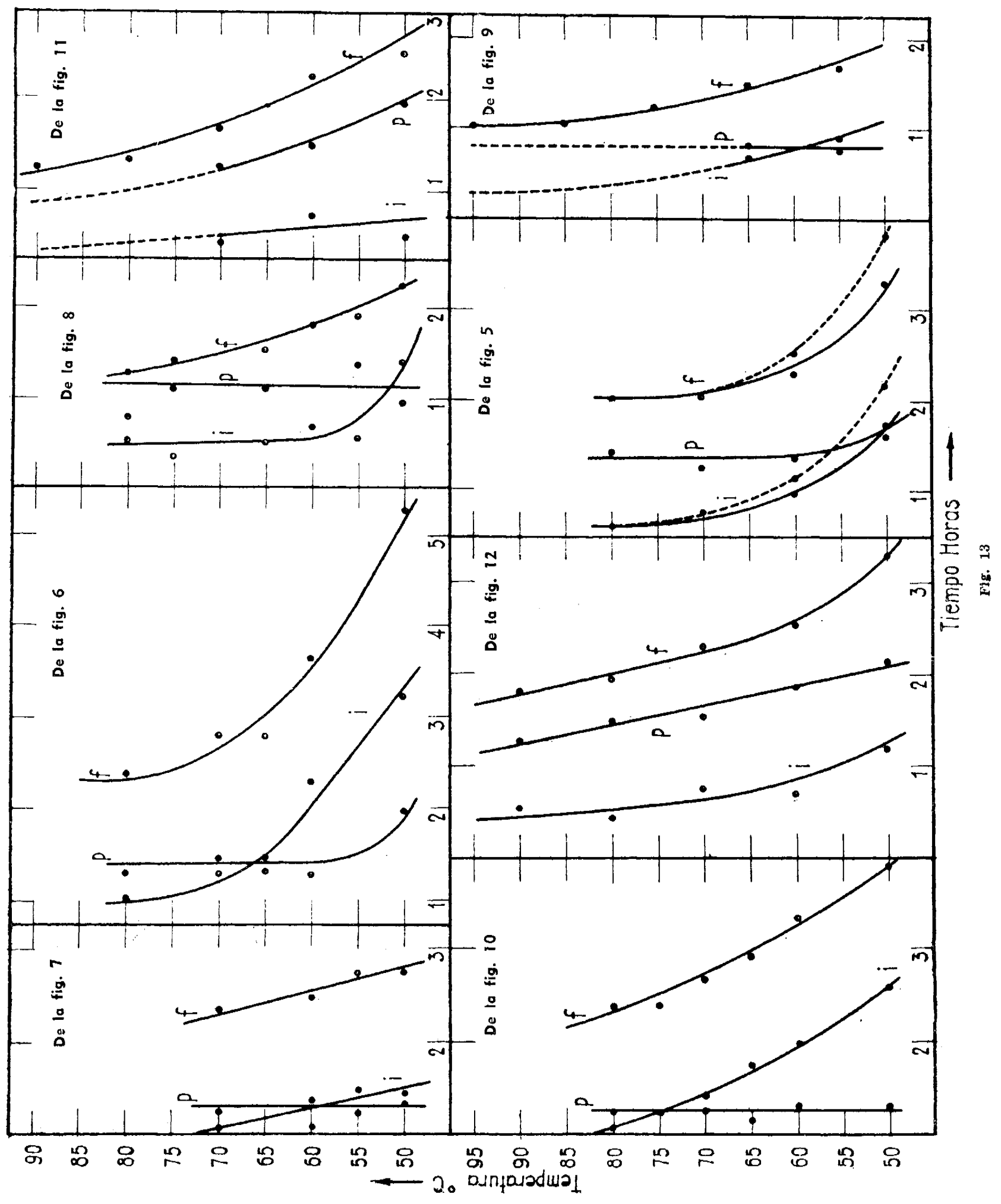




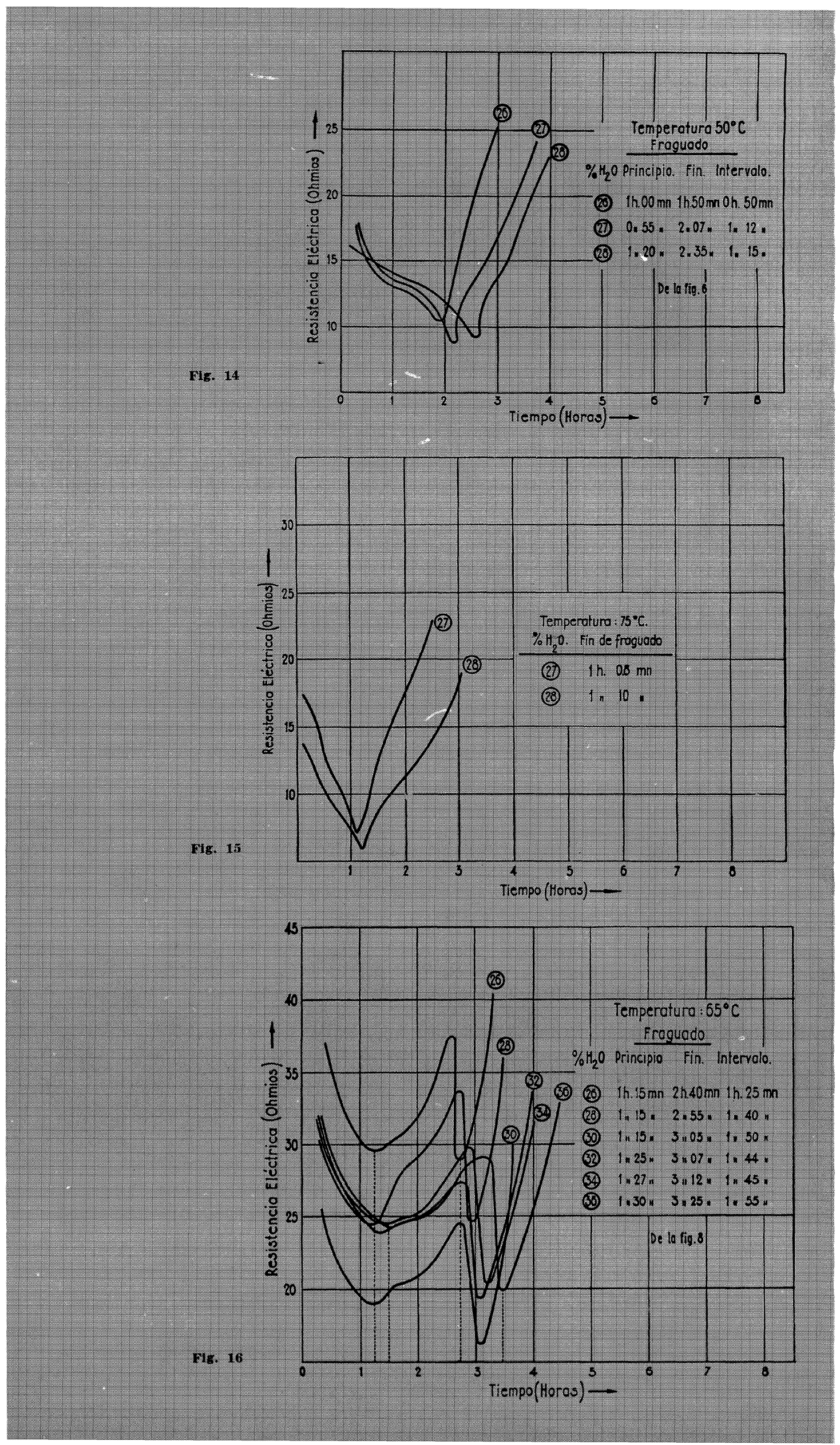




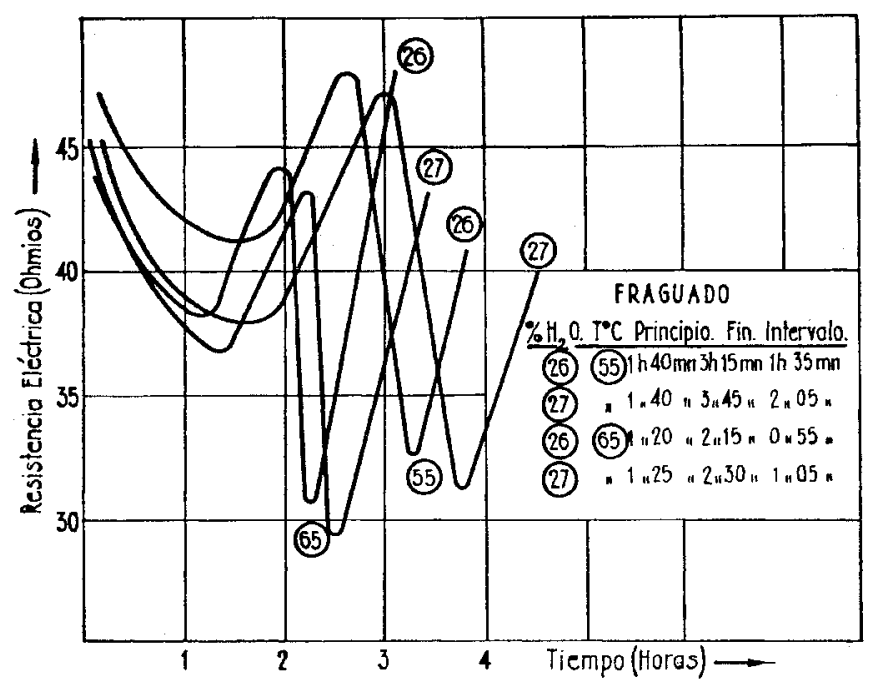

Fig. 17

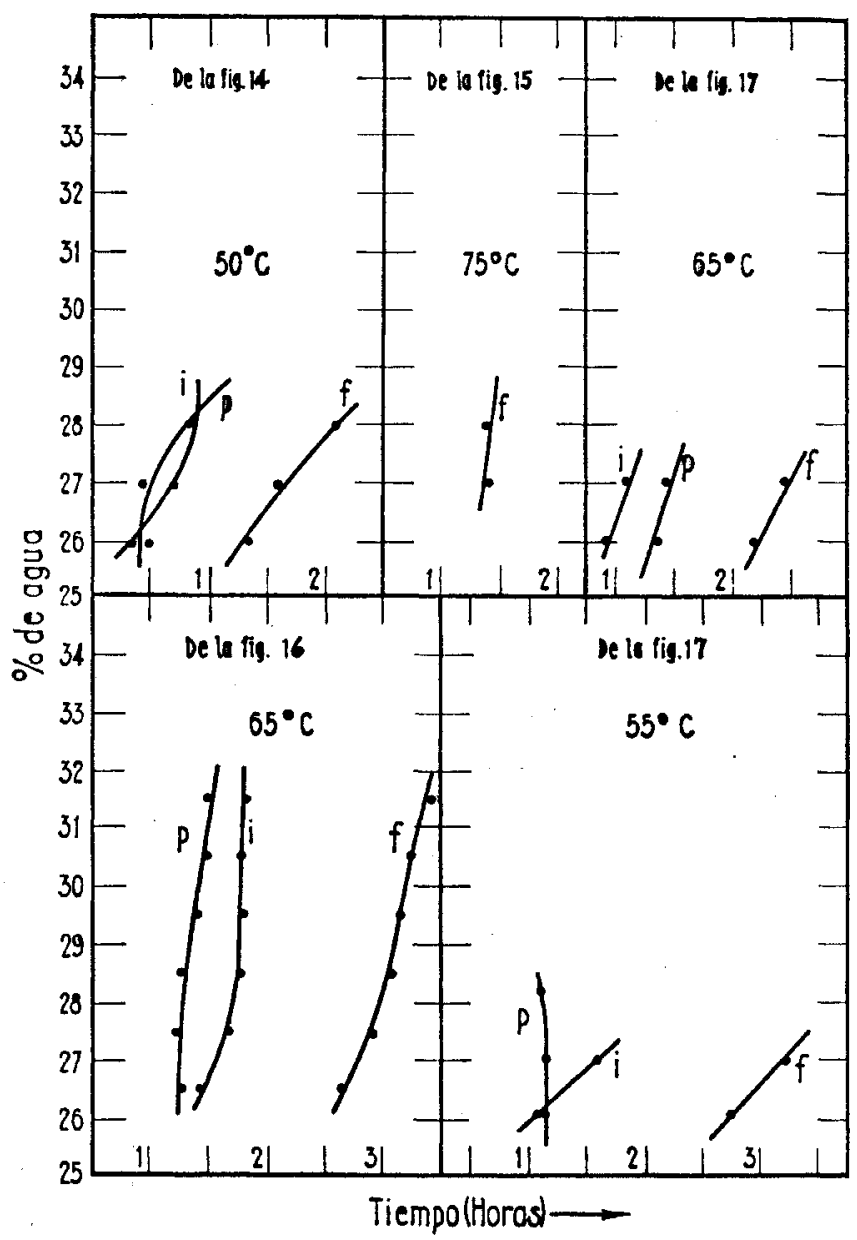

Fig. 18 


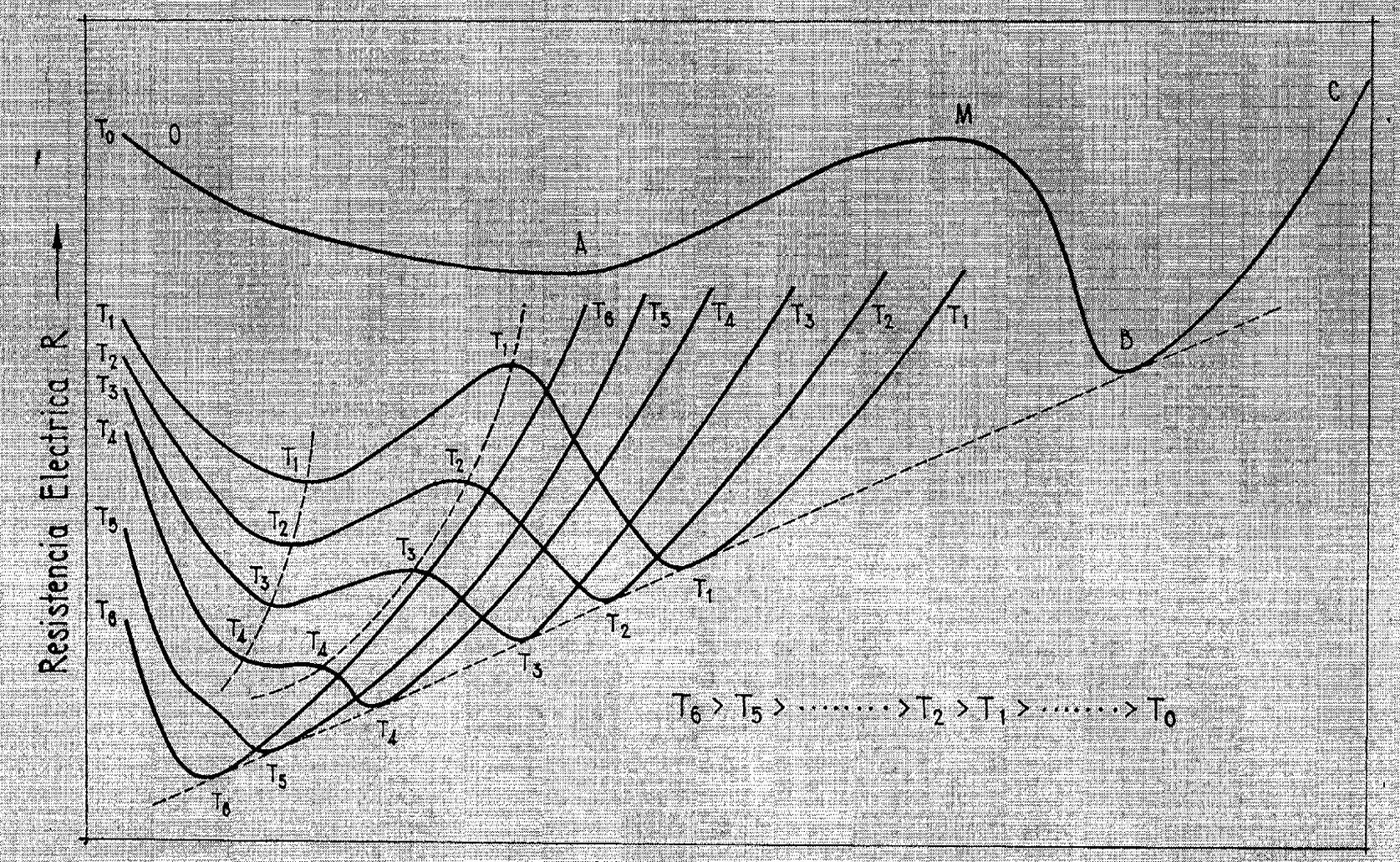

Tiempo $t$

nig. 19

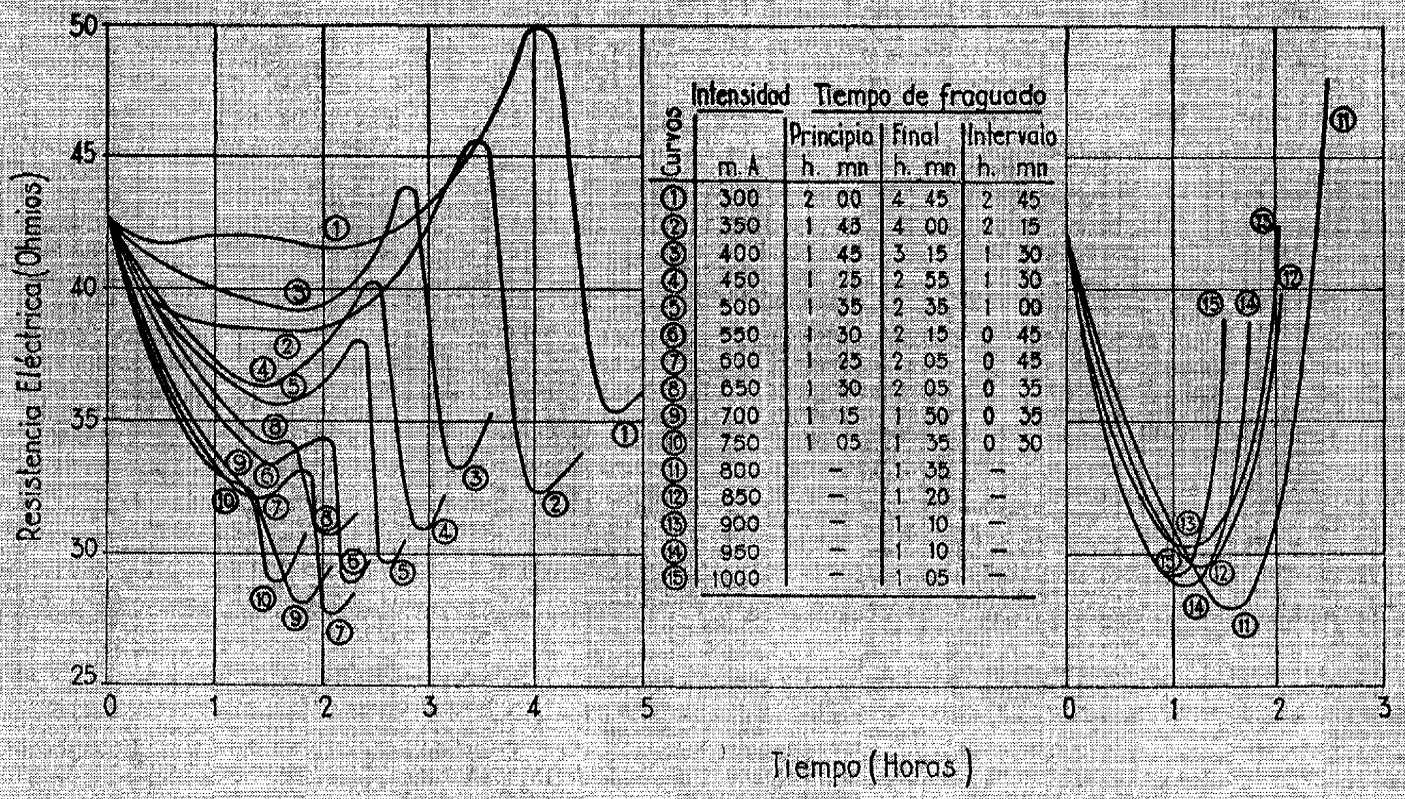

Frg. 20 


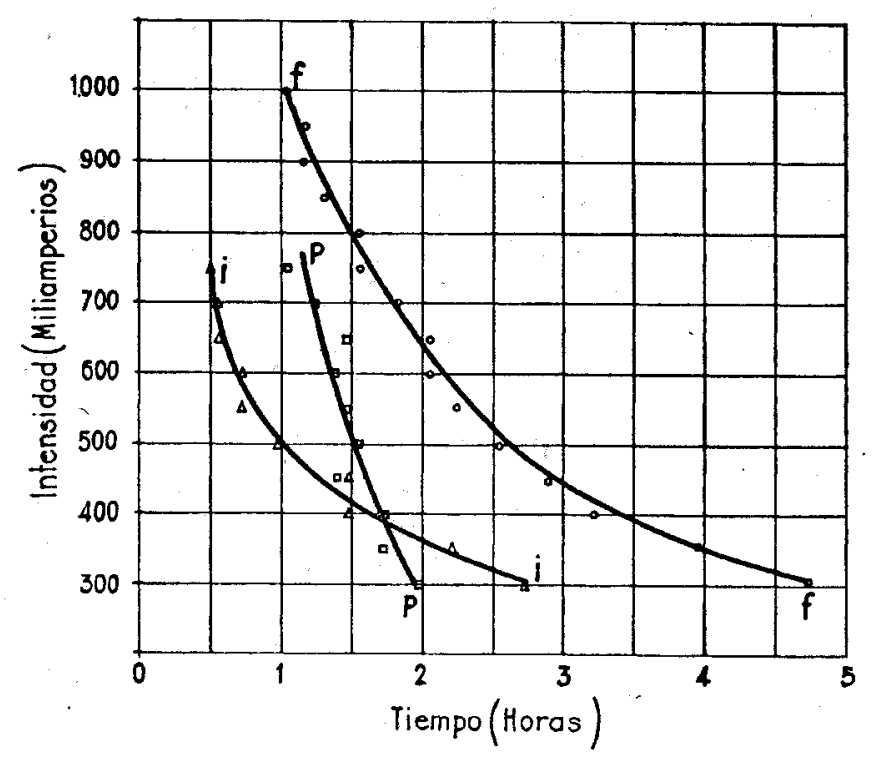

Fig. 21

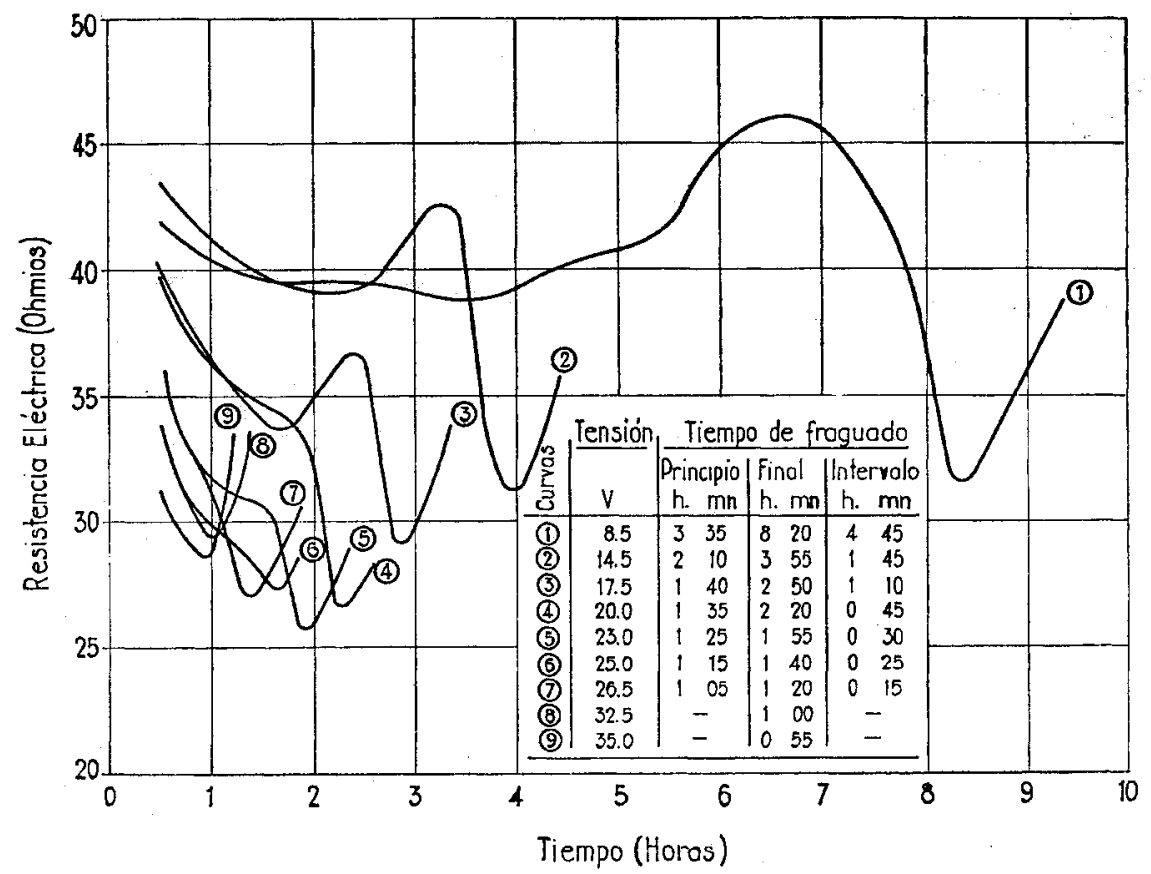

Fin. 22

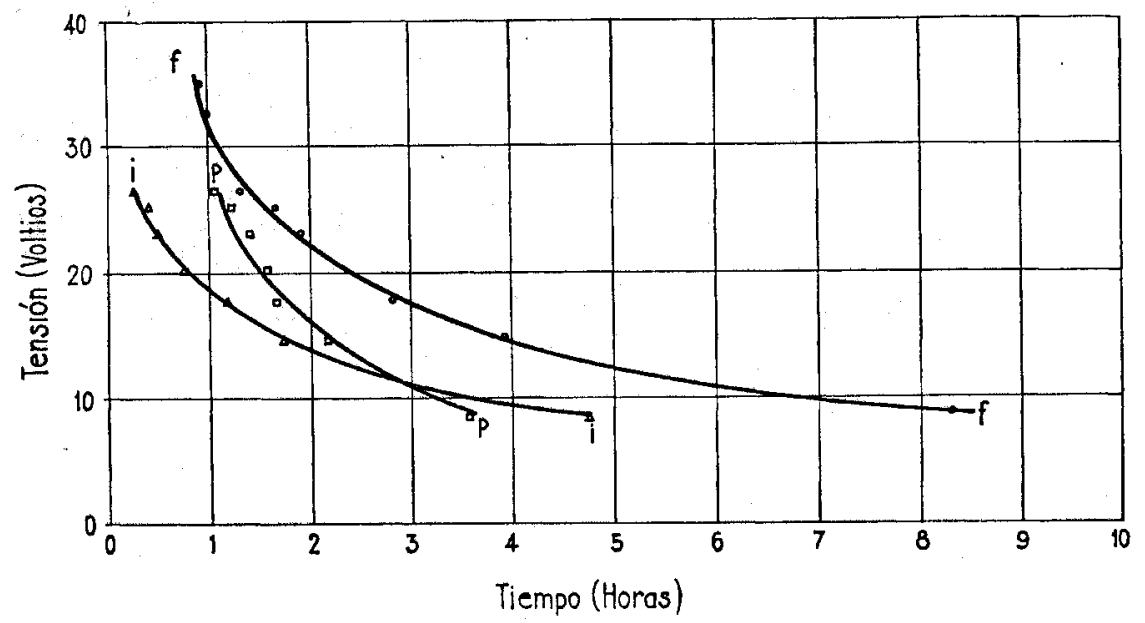

Fig. 23 


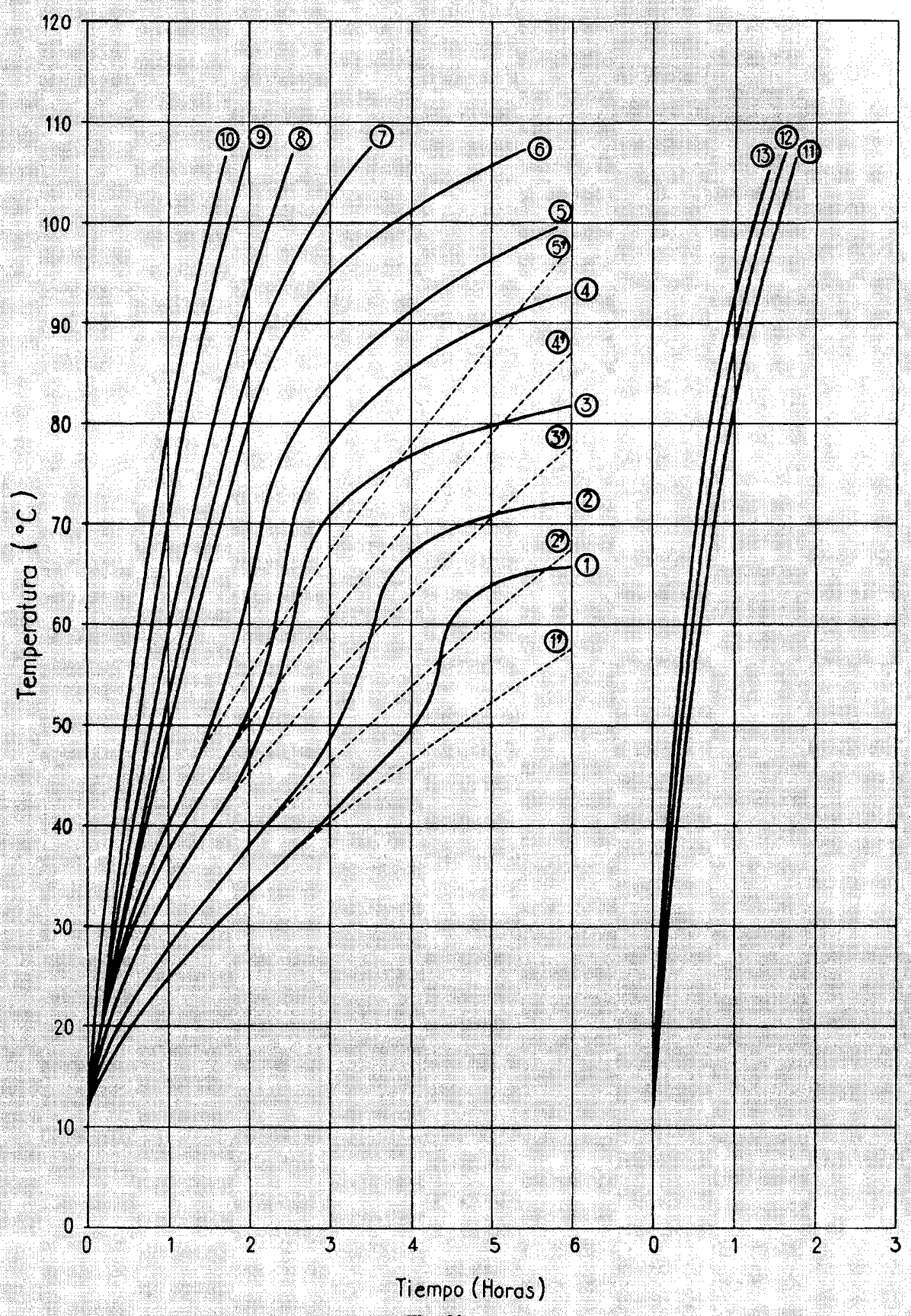

73 


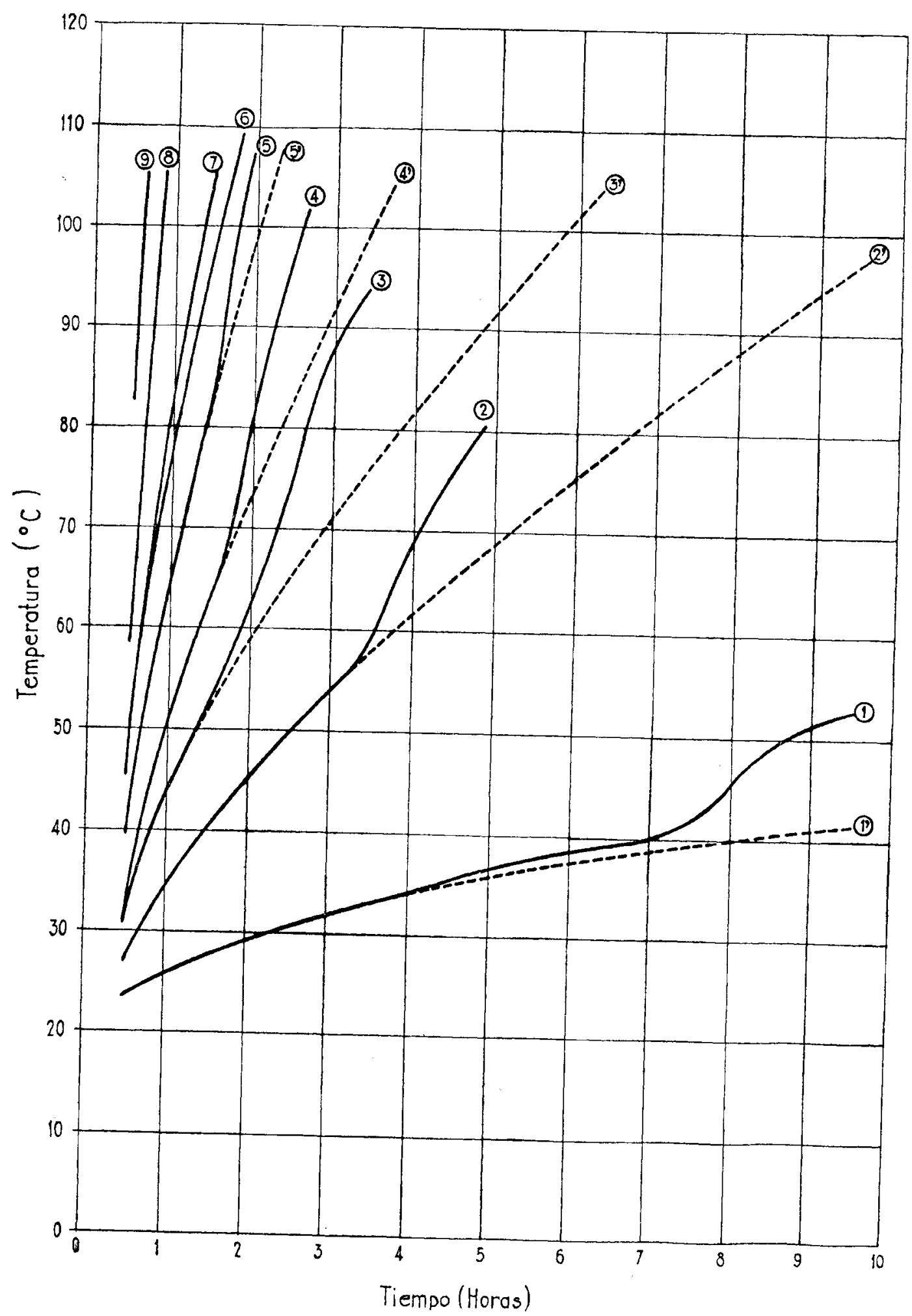

Fig. 25 
Igualmente presta esta técnica una ayuda especial cuando la aportación de calor se hace mediante calefacción eléctrica, demostrando que los efectos conseguidos son análogos a los logrados por otro procedimiento cualquiera de calefacción.

En efecto, en condiciones casi adiabáticas las curvas resistencia eléctrica-tiempo a intensidad constante presentan el aspecto de la figura $20 \mathrm{y}$ los principios, finales e intervalos de fraguado respecto de la intensidad, se sitúan en curvas de la forma indicada en la figura 21 ; a tensión constante las curvas equivalentes son las de las figuras 22 y 23 , respectivamente. En cada caso, las curvas temperatura-tiempo son del tipo de las representadas en las figuras 24 y 25 .

Las conclusiones que pueden deducirse del análisis de estas curvas son las mismas que cuando la calefacción se efectúa por otros medios, de lo cual se infiere que el fraguado acelerado por efecto Joule es cualitativamente análogo al acelerado por cualquier otro tratamiento térmico, siempre que las condiciones higrométricas del ambiente y del hormigón sean comparables.

(Continuará) 